\title{
ФЛУКТУАЦИОННЫЕ ХАРАКТЕРИСТИКИ АВТОДИННЫХ РАДИОЛОКАТОРОВ С ЧАСТОТНОЙ МОДУЛЯЦИЕЙ
}

\author{
В. Я. НОСКОВ ${ }^{1}$, А. С. ВАСИЛЬЕВ ${ }^{2}$, Г. П. ЕРМАК ${ }^{2}$, К. А. ИГНАТКОВ ${ }^{1}$, А. П. ЧУПАХИН ${ }^{1}$ \\ ${ }^{1}$ Уральский Федеральный университет имени первого Президента России Б. Н. Ельичина, \\ Россия, Екатеринбург, 620002, ул. Мира, 19 \\ ${ }^{2}$ Институт радиофизики и электроники Национальной Академии наук Украины, \\ Украина, Харьков, 61085, ул. Проскуры 12
}

\begin{abstract}
Аннотация. Разработана математическая модель автодинного радиолокатора с частотной модуляцией. Модель представлена в виде автогенератора с одноконтурной колебательной системой, перестраиваемого по частоте изменением емкости варикапа. Учтено воздействие на генератор собственного отраженного от объекта локации излучения и внутренних шумов генератора, а также шумов источника питания. Получены основные выражения для расчета сигнала сопутствующего паразитного отклика генератора, составляющих полезного сигнала и шума при регистрации автодинного отклика, как в цепи питания, так и по изменению амплитуды колебаний. Выполнены расчеты шумовых характеристик при малых и больших значениях параметра обратной связи. Установлено явление периодической нестационарности уровней шума на выходе автодинного генератора при условиях сильной обратной связи. Результаты расчетов и экспериментов получены для автодина, выполненного на диоде Ганна 8-мм диапазона.
\end{abstract}

Ключевые слова: автодин; частотная модуляция; автодинная СБРЛ с ЧМ; сигнальные характеристики АСБРЛ с ЧМ; параметры АСБРЛ с ЧМ; генератор на диоде Ганна

Автодины благодаря совмещению в одном каскаде - автогенераторе — функций передатчика зондирующего и приемника отраженного от объекта электромагнитного излучения обеспечивают конструктивную простоту, компактность и относительно низкую стоимость СВЧ модуля. Поэтому данные устройства широко используются в тех системах, в которых эти качества являются определяющими. Например, в радиолокационных взрывателях боеприпасов, измерительной аппаратуре для про- ведения аэробаллистических испытаний, охранных устройствах, датчиках и измерителях параметров технологических процессов и на транспорте [1-5].

Практические условия работы в различных применениях часто накладывают на автодинные системы особые требования. К ним относятся:

- реализация высокой чувствительности системы для обнаружения объектов на относительно большом расстоянии при наличии под-

* Работа выполнена в соответствии с Договором о научно-техническом сотрудничестве между УрФУ и ИРЭ НАНУ, а также при финансовой поддержке Правительства Российской федерации, постановление № 211 контракт № 02.A03.21.0006. 
Vilnius. — IEEE, 2010. - Vol. 2. - P. 406-409. — URL : http://ieeexplore.ieee.org/document/5547497/.

2. Kim, S; Kim, B.-H.; Yook, J.-G.; Yun, G.-H. Proximity Vital Sign Sensor Using Self-Oscillating Mixer. URSI Asia-Pacific Radio Science Conference (URSI AP-RASC). - 2016. - P. 1446-1448. - DOI: 10.1109/ URSIAP-RASC.2016.7601402.

3. Носков, В. Я.; Игнатков, К. А.; Чупахин, А. П. Применение двухдиодных автодинов в устройствах радиоволнового контроля размеров изделий. Измерительная техника. - 2016. - № 7. - C. 24-28. - DOI: 10.1007/s11018-016-1035-9.

4. Ermak, G. P.; Popov, I. V.; Vasilev, A. S.; Varavin, A. V.; Noskov, V. Ya.; Ignatkov, K.A. Radar sensors for hump yard and rail crossing applications. Telecom. Radio Eng. - 2012. - Vol. 71, No. 6. - P. 567-580. — DOI : 10.1615/TelecomRadEng.v71.i6.80.

5. Носков, В.Я.; Варавин, А.В.; Васильев, А.С.; Ермак, Г.П.; Закарлюк, Н. М.; Игнатков, К. А.; Смольский, С.М.Современные гибридно-интегральные автодинные генераторы микроволнового и миллиметрового диапазонов и их применение. Часть. 9. Радиолокационное применение автодинов. Усnехи современной радиоэлектроники. - 2016. - № 3. C. $32-86$.

6. Komarov, I. V.; Smolskiy, S. M. Fundamentals of Short-Range FM Radar. Norwood : Artech House, 2003. - 289 p. - DOI : 10.1109/MAES.2004.1346903.

7. Воторопин, С.Д.; Носков, В.Я.; Смольский, С.М.Анализ автодинного эффекта генераторов с линейной частотной модуляцией. Известия вузов. Физика. - 2008. - T. 51, № 6. - C. 54-60. - URL : http:// elibrary.ru/item.asp?id=11135288.

8. Noskov, V. Ya.; Ignatkov, K. A.; Chupahin, A. P.; Vasiliev, A. S.; Ermak, G. P.; Smolskiy, S. M. Peculiarities of Signal Formation of Autodyne Radars with Linear Frequency Modulation. Вестник НТУ Украины «КПИ». Серия Радиотехника, Радиоаппаратостроение. 2016. — № 67. - C. 50-57. — http://radap.kpi.ua/en/ radiotechnique/article/view/1366

9. Носков, В. Я.; Игнатков, К. А. Особенности шумовых характеристик автодинов при сильной внешней обратной связи. Известия вузов. Физика. - 2013. — T. 56, № 12. - C. 112-124. - URL : http://elibrary. $\mathrm{ru} / \mathrm{item} \cdot \mathrm{asp} \mathrm{id}=21125997$.

10. Noskov, V. Ya.; Ermak, G. P. Signal and fluctuation characteristics of autodyne vibration and displacement meters. Telecom. Radio Eng. - 2014. Vol. 73, No. 19. - P. 1727-1743. - DOI : 10.1615/ TelecomRadEng.v73.i19.30.

11. Носков, В.Я.; Игнатков, К.А.О применимости квазистатического метода анализа автодинных систем. Известия вузов. Радиоэлектроника. - 2014. — T. 57, № 3 - C. 44-56. - URL : http://radio.kpi.ua/ article/view/S0021347014030054.

12. Noskov, V. Ya.; Ignatkov, K. A. Autodyne signa1s in case of random delay time of the reflected radiation. Telecom. Radio Eng. — 2013. — Vol. 72, No. 16. - P. 
1521-1536. - DOI : 10.1615/TelecomRadEng.v72.i16. $\underline{70}$.

13. Varavin, A. V.; Vasiliev, A. S.; Yermak, G. P.; Popov, I. V. Autodyne Gunn-diode transceiver with internal signal detection for short-range linear FM radar sensor. Telecom. Radio Eng. - 2010. - Vol. 69, No. 5.
—P. 451-458. - DOI : 10.1615/TelecomRadEng.v69.i5. $\underline{80 .}$

14. Носков, В. Я.; Игнатков, К. А. Шумовые характеристики автодинов со стабилизацией частоты внешним высокодобротным резонатором. Радиотехника и электроника. - 2016. - Т. 61, № 9. - С. 905-918. — DOI: 10.7868/S0033849416090102.

Поступила в редакцию 23.05.2016 